\title{
Ethical responsibilities of European children's teams facing the resurgent COVID-19 pandemic
}

\author{
Anna Zanin ${ }^{1}$ (D) Enrico Furlan ${ }^{2} \cdot$ Marek Migdal $^{3} \cdot$ Joe Brierley $^{4,5}$
}

Received: 25 February 2021 / Revised: 15 May 2021 / Accepted: 24 June 2021 / Published online: 9 July 2021

(c) The Author(s), under exclusive licence to Springer-Verlag GmbH Germany, part of Springer Nature 2021

\begin{abstract}
The COrona VIrus Disease 2019 (COVID-19) pandemic is posing an unprecedented challenge to healthcare systems around the globe. Europe has been struggling for 1 year now, and despite some encouraging progress (above all, the beginning of vaccination), the second wave is ongoing. Even though children are less affected than adults, the COVID-19 pandemic—and in particular the measures to counter it—is having a considerable impact on the paediatric healthcare setting. It is, therefore, the duty of paediatric teams in Europe to prepare for the challenges ahead. We wish to contribute to this necessary preparedness in two ways: firstly, by assessing the direct and indirect impact of the pandemic on children and on the paediatric setting; secondly, and more importantly, by identifying the various responsibilities of paediatric healthcare professionals, in light of established ethical principles. Only abiding by these responsibilities will it be possible to ensure that ill children and their families are properly supported even in these difficult times and to grant that decisions about children's healthcare remain morally justified and lawful.
\end{abstract}

\section{What is Known:}

- The COVID-19 outbreak is posing an unprecedented challenge to healthcare systems around the globe

- Despite the children are less affected than adults, the COVID-19 pandemic is having a huge impact also on paediatric setting

What is New:

- The COVID-19 pandemic lays out specific responsibilities of paediatric professionals towards our pa-tients, society and ourselves

- The paediatric teams in Europe should assess the direct and indirect impact of the pandemic on the chil-dren and on the paediatric settings,

ensuring consistency between centres and across regions in Europe

Keywords COVID-19 $\cdot$ Ethics $\cdot$ Paediatrics $\cdot$ Neonatology $\cdot$ Healthcare professionals' responsibilities

\section{Abbreviations}

AICU

ARDS

COVID-19

Adult intensive care unit

Acute respiratory distress syndrome

COrona-Virus-Disease-19

Communicated by Piet Leroy

Anna Zanin

anna.zanin@aopd.veneto.it

Enrico Furlan

enrico.furlan@unipd.it

Marek Migdal

m.migdal@ipczd.pl

Joe Brierley

joe.brierley@gosh.nhs.uk

1 Paediatric Intensive Care Unit, San Bortolo Hospital, Vicenza, Italy
HCWs Healthcare workers

ICU Intensive care unit

LTV Long-term ventilation

MERS Middle East Respiratory Syndrome

NICU Neonatal intensive care unit

PICU Paediatric intensive care unit

2 Research Group "Moral Philosophy and Bioethics", Department of Molecular Medicine, University of Padova, Padova, Italy

3 Department of Anaesthesiology and Intensive Care, Children's Memorial Health Institute I IPCZD, Warsaw, Poland

4 Paediatric Intensive Care, Great Ormond Street Hospital for Children, London, UK

5 Paediatric Bioethics Centre, Great Ormond Street Hospital for Children, London, UK 


$\begin{array}{ll}\text { PPE } & \text { Personal protect equipment } \\ \text { SARS } & \text { Severe acute respiratory syndrome } \\ \text { SARS-CoV-2 } & \text { Severe Acute Respiratory Syndrome } \\ & \text { Coronavirus 2 } \\ \text { WHO } & \text { World Health Organization }\end{array}$

\section{Background}

Since the outbreak of the severe acute respiratory syndrome coronavirus 2 (SARS-CoV-2) in China, in December 2019, the virus causing COrona-Virus-Disease-19 (COVID-19) has spread rapidly becoming a global pandemic [1].

As of May 2021, over 150 million cases of COVID19 and more than 3.2 million deaths have been reported worldwide [2]. Europe has been one of the first affected continents, in terms of both COVID-19-related deaths and patients who needed admission in intensive care units (ICUs) [3]. The most severely affected populations continue to be older citizens and patients with pre-existing complex health problems [4].

Children have generally had milder manifestations compared to older patients [5, 6]. Although children can transmit the SARS-COV-2 virus (even if asymptomatic), they are not the main drivers of the pandemic [7, 8]. Furthermore, $<2 \%$ of affected children were admitted to the paediatric intensive care units (PICUs). The most commonly described symptoms are fever and cough, with only $0.6 \%$ of patients progressing to acute respiratory distress syndrome (ARDS) or multi-organ system dysfunction [9]. There have been case reports of neonates infected, with concerns about vertical and perinatal transmission $[10,11]$. However, some children have been affected by the novel likely post-COVID-19 multisystem hyper-inflammatory paediatric syndrome (MIS-C/ PIMS-TS), which was initially reported in Europe [12-14]. The long-term outcome of both acute COVID-19 infection in children and MIS-C remains unknown, but acute mortality has been thankfully rare. Surprisingly, this includes children expected to do badly in any acute infective pandemic, such as those living on organ support or immunosuppression [15].

Given this scenario, one might conclude that children are only marginally affected by the COVID-19 pandemic and that the paediatric setting in Europe should be reassured about the impact of the second wave on their activities, or more generally about the healthcare of the young. The Ethics Section of the European Society of Paediatric and Neonatal Intensive Care (ESPNIC) warned very early on, in March 2020, against such a potentially dangerous evaluation [16], which exempts healthcare professionals (HCPs) from preparing for future waves and from tackling present though subtle challenges.

In order to contribute to the necessary effort toward preparedness, in this paper, we set out to do two things: firstly, to carefully assess the impact of the pandemic (and of the measures to address it) on paediatric health services and on children's health; secondly, and more importantly, to identify the various ethical responsibilities of paediatric HCPs, making reference to well-established medical ethics principles, reinterpreted in light of the specific challenges posed by the pandemic $[17,18]$.

\section{Impact of the COVID-19 pandemic on the paediatric setting}

\section{Impact on bed capacity, organization, and territorial services}

In the first phase of the pandemic, many national health systems restricted the access of minors to hospital settings as much as possible, unless treatments were essential. As a consequence, there was a large-scale reduction of elective procedures and a postponement of non-urgent consultations, missed or delayed opportunities for semi-elective surgery or other procedures [19-21]. Some appointments were, and continue to be, replaced by online communication systems [22-24]. The benefits of this approach include decreased cost, and avoiding the need for parents to travel to the hospital or clinic with children who may have complex health problems, including infection risks [25-27]. However, such benefits must be balanced with the lack of direct clinical examination and of the opportunity to observe the interaction within families. This lack of direct contact may result in missed diagnostic opportunities and in the impossibility to detect child-abuse and domestic violence [28-30].

Support for families already struggling with either financial or taxing healthcare demands has been impacted at a time of already reduced public support. Some children have been, and continue to be, harmed by not being able to access needed treatment in a timely fashion $[31,32]$.

The number of severe adult COVID-19 cases seen in many European countries brought massive demand for ICU beds that far exceeded capacity, threatening to overwhelm healthcare systems [33-35]. Several European PICUs had to accept adult patients, in order to support adult ICU colleagues during peak demand; in other cases, paediatric intensivists, anaesthetists, and PICU nurses were redeployed to adult units [21]. Even specialized PICU and NICU transport services were reorganized and used to grant transfers of adults [36].

Thankfully, paediatric acute ICU admissions were lower than in equivalent periods of the year before the pandemic [37], perhaps also thanks to hard lockdown measures [38, 39]. There are several reports discussing the reorganisation of whole departments repurposed for the care of adults [33-35], putting children at a disadvantage during the first and second wave. 
It is difficult to preview the impact of this redeployment in future waves, but the fact that 'paediatric' resources might be harder to 'lend' to adult patients, given the growing impact of the pandemic on child-health and children's services, should be taken into consideration.

\section{Physical, psychological, and moral impact on healthcare professionals}

HCPs are one of the most infected populations, as during previous pandemic viral infections [40]. As the Middle East Respiratory Syndrome (MERS) and the Severe Acute Respiratory Syndrome (SARS) outbreaks, when the percentage of infected HCWs was around 20\% [41].

As of 3 September 2020, 7000 COVID-19 deaths among HCPs were reported worldwide [42, 43]. Staff sickness and shielding, due to the combination of resurgent COVID19 and of the need to catch up with previously postponed healthcare interventions, may seriously affect the paediatric setting and compromise its services $(31,44)$. The impact on various routine and urgent diagnostic procedures and tests especially during lockdowns $(31-32,44-45)$ was described as one of the unintended consequences of the pandemic.

Along with physical impairment, there is a high risk of burnout, due to the demanding shifts, to the shortage of staff, space, and supplies, and to the sense of impotence facing the tragic loss of human lives [42]. Nurses, for instance, are confronted with unprecedented forms of moral distress [43], and HCPs working in ICUs have had to take up the excruciating moral burden of allocating insufficient life-saving resources $[46,47]$. Since these workers have not had yet the chance to properly process what they have experienced, they are at unprecedented risk of moral injury and mental health issues, making efforts to prevent or mitigate these phenomena very urgent [47]. Personal safety aside and HCWs are also worried about the possibility of infecting their loved ones, when they go home [49-51].

For these reasons, the first experiences of programmes aimed at protecting HCW's well-being are welcome and must be encouraged. Peer support groups have been created to provide practical and concrete solutions, allowing time to process difficult experiences, to share effective interventions, and to foster collaboration [51].

\section{Impact on children and families}

Whilst COVID-19 has not directly harmed a large number of children, paediatric teams must be aware of the overall indirect effects on the young.

Decreasing the number of visitors, including parents, for critically ill children may become again partially necessary in case of new acute crises. Yet, this is clearly at odds with the usual family-centred care practised in most European children's PICUs [52]. Mitigation is therefore vital and might include the adoption of new communication devices: despite the impediments of distance and PPE, a transparent dialogue with children and their families must be maintained. To this aim, recourse to usual bioethics support and to multidisciplinary teams, even via video conferencing, is highly advisable.

Social distancing and economic shutdown lead to a significant change to the psychosocial environment of most European countries, with possible consequences on the mental health of children and adolescents [53]. Several governments temporarily closed educational institutions to contain the spread of the pandemic, impacting over $60 \%$ of the world's student population [54]. Consequences on children's mental health by lack of education and sports routine have been heavy especially in children with special needs, minors with a migrant background, and/or low socioeconomic status: for some children, home can be isolating and even dangerous because of a complex combination of potentially negative family interactions, economic uncertainty, stress, anxiety, and a more limited access to resources [55-57]. This situation can lead to an increased risk of parental mental illness, domestic violence, and child abuse [55-59]. Another problematic consequence of the pandemic is the drop in routine vaccination [60], especially given the pre-existing vaccine hesitancy across much of Europe [61-63].

For this reason, paediatric teams need to have a lower than usual threshold in considering non-accidental injuries, domestic violence, and self-harm in children [53] together with a strong implementation of the COVID-19 vaccination campaign [63].

\section{Responsibilities of paediatric healthcare professionals}

The extraordinary times we are living in do not change the moral principles and values we are committed to [64, 65]. Still, they do force us to clarify the implications of such principles in light of the new circumstances and to lay out our specific responsibilities towards our patients, society and ourselves.

Even during a pandemic, we need to make sure that our decisions remain morally justified and that they are taken through a process that is reasonable, open and transparent, inclusive, and that grants accountability [66].

Many have already attempted to determine the criteria for ethical decision-making during the COVID-19 pandemic, especially when dealing with excruciating allocation decisions in the adult intensive care setting [46, 47, 67]. However, little attention has been dedicated to the paediatric environment. 


\section{Responsibilities towards paediatric patients and their families}

To practically determine how to respect the dignity of each child and their families, we continue to refer to established bioethics principles: beneficence (appropriateness and proportionality), autonomy (moral agency), and justice [65].

Firstly, paediatric HCWs have the duty to benefit their patients by proposing the treatment options which are best for their medical condition, after weighing up potential benefits and burdens. Of course, the exceptional circumstances of a pandemic (e.g., the increased risks connected to hospitalization during an infectious disease outbreak) must be factored in when determining the proportionality of a treatment.

Secondly, we respect patients by recognizing and promoting their autonomy or moral agency or the autonomy of their legal representatives, usually parents. Again, the circumstances created by the pandemic must be seriously taken into consideration, promoting - when necessary-new forms of discussion (e.g., teleconference), compatible with the emergency.

Thirdly, we respect the equal dignity of every child by granting fair access to healthcare resources, while at the same time making sure that we use the limited resources of society efficiently. From this point of view, it is paramount that we offer our patients only appropriate and proportional treatments; otherwise, we not only breach the principle of beneficence (and its corollary of avoiding non-beneficial interventions) but also the principles of justice and solidarity. During a pandemic, it is even more evident that inappropriately using a scarce resource means depriving others who are in desperate need of them, and who can benefit from them. However, it must be clearly stated that when discussing possible limitation of treatments, we are not asking if a child is worth treating, but if the treatment is proportionate or worthwhile, all thing considered. Therefore, for instance, when intensive care treatments are deemed not appropriate or not proportionate, it is our duty to ensure the continuation of the best possible care by redirecting treatment and entrusting the child and her family to palliative care colleagues.

Furthermore, before opening up any discussion of possible prioritization of paediatric patients in case of a severe shortage of healthcare resources, we have the duty to make every possible effort to maintain the present level of healthcare services, so as to grant all children the appropriate and proportional treatments they need. If, for example, certain paediatric healthcare services cannot be safely delivered in the hospital setting, it is the HCPs' responsibility to promote the timely activation of appropriate treatments and care (including palliative care) at the child's home. A time of crisis can be a time of moral and organizational creativity.

It is therefore essential to support an ongoing discussion on the gaps of the current organization of our paediatric services [68] and to closely monitor the various efforts to promote home-based care services for children with chronic diseases [69].

Given the rather scattergun approach of much of the world to assessing the efficacy of treatments for COVID19 , it is unsurprising that children have been even less wellserved by randomized controlled trials of therapies in either COVID-19 infection or PIMS-TS/MIS-C. A clear ethical standard is for paediatric teams to (i) always enrol affected patients into any available RCTs and (ii) to push for suitable trails of candidate therapies in their patients. Consideration of novel/innovative/compassionate use treatments should only occur in the absence of appropriate RCTs.

Finally, seeking ethics advise, whenever necessary, from competent bodies and professionals (such as healthcare ethics committees and/or clinical bioethicists) seems even more critical in a time of increased uncertainty and high psychological and moral pressure. In the last few months, changes in standard practice have been introduced as a consequence of new visiting policies and of staff redeployment.

Even in the midst of challenging reorganisations, clinicians should continue resorting to an interprofessional shared decision-making model in order to guarantee an optimal exchange of information, the chance of proper shared deliberation leading to carefully considered treatment decisions.

\section{Responsibilities towards society}

Especially during a pandemic that directly and indirectly impacts on the paediatric setting, we have the responsibility to assure society that we will remain faithful to our commitment of caring for critically ill and also chronic children (both cared for in hospitals and at home) and of advocating for their needs and rights. While remaining collaborative and ready to do our part to face the emergency, it is also necessary to pressure governments and healthcare institutions to ensure they provide us with the means, including adequate personnel, to provide the safe continuation of optimal care (both primary and home care).

This responsibility includes ensuring that we protect paediatric services, including our staff, and make it a European and National priority as we emerge from lockdown, and catch up with the paediatric care that has been put on hold for many months. Children continue to pay a great price to mitigate the impact of what is mostly an adult disease, in terms of their psychological health, access to school, social life, and overall welfare. If this pandemic had affected in a stronger way children, probably, we would be prioritising them as the weakest and most vulnerable. The dignity and value of the human versus any utilitarian perspective crash with standard pandemic planning and the theme of 
allocation of resources to those with a greater chance of functional survival [70].

Society has a responsibility to its young to minimize the effects of this situation on them, and paediatric healthcare professionals must be powerful advocates for children during this pandemic.

\section{Responsibilities of healthcare professionals towards themselves}

Last but not least, HCPs have the duty to protect and promote their own physical and psychological safety.

This can be achieved first of all by using personal protective equipment (PPE) and by receiving systematic testing (it is, therefore, a primary responsibility of governments and healthcare institutions to grant them) $[40,41]$ and vaccination [63]. Though medical staff are prioritized in many countries, PPE shortages have been reported in many healthcare settings and testing is often not as timely as necessary [71]. Vaccine hesitancy remains a barrier to full population inoculation: several concerns about the safety of COVID-19 have been raised. A recent report highlighted how HCPs not caring for SARS-CoV-2 positive patients expressed higher levels of vaccine hesitancy [62]. Educational campaigns are important to combat misinformation and avoid low inoculation rates in populations at risk with the dual objectives to maintain HCPs and patients safety [61].

Additionally, physical and psychological safety can be maintained only by keeping shifts within a reasonable time limit (max $12 \mathrm{~h}$ ) and by providing all healthcare staff with emotional, pastoral and ethics support, including appropriate pre-briefing and debriefing in line with best practice.

Furthermore, there is a special duty to protect trainees (e.g., medical/nursing students) and residents, by involving them adequately, i.e., by not asking them to undertake activities that are beyond their level of competence. Trainees must be advised that they should seek senior workplace guidance whenever necessary. They are the HCPs of the future and must not be harmed by overwhelming experiences.

Continuous training is particularly important during an infectious disease outbreak. It must focus, among other things, on the appropriate use of PPE, infection-control measures, and how to deal with risky procedures (e.g., intubation of COVID-19 patients).

\section{Summary}

The COVID-19 pandemic is a global threat which is putting healthcare systems under enormous pressure. Children have been less severely affected by direct COVID infection compared to older adults, though the emergence of novel PIMS-TS/MIS-C has been a challenge.
As the situation worsens, paediatric teams in Europe must prepare for the challenges ahead, firstly by assessing the direct and indirect impact of the pandemic on the children, and secondly, by taking up their various responsibilities, especially that of interpreting established ethical principles in light of the new circumstances in which they have to operate, while remaining faithful to the commitment to respect each child and their dignity.

Only abiding by these responsibilities will it be possible to guarantee that ill children and their families continue to be properly supported even in this predicament, to ensure that HCPs themselves are adequately sustained and protected, and to grant that decisions about children's healthcare remain morally justified and lawful.

\section{Acknowledgements ESPNIC Ethic section}

Authors' contributions Joe Brierley-Identified the need for an international collaborative statement as Chair of Ethics section of the ESPNIC Society, Chair RCPCH group, authored latest UK DtLt guidance. Revised and amended the initial manuscript. Marek Migdal-Deputy Chair of the ESPNIC Ethics Section, coordinated collaborations and revised the manuscript. Anna Zanin-Member of ESPNIC Ethics Section, designed and drafted the initial manuscript, and reviewed and revised the manuscript. Enrico Furlan-Moral philosopher, codesigned and co-drafted the section on moral responsibilities. Reviewed and revised the manuscript. All authors approved the final manuscript as submitted and agree to be accountable for all aspects of the work.

\section{References}

1. WHO (2020) COVID-19 is a Pandemic. https://who.int/docs/ default-source/coronaviruse/situation-reports/20200330-sitrep70-covid-19.pdf?sfvrsn=7e0fe3f8_4. Accessed 15 May 2021

2. ECDC (2021) COVID-19 situation update worldwide as of week 24 updated 24 June 2021. https://www.ecdc.europa.eu/en/geographicaldistribution-2019-ncov-cases. Accessed 15 May 2021

3. JHU (2020) COVID-19 Dashboard by the Center for Systems Science and Engineering (CSSE) at Johns Hopkins University (JHU). https://coronavirus.jhu.edu/map.html

4. Huang C, Wang Y, Li X, Ren L, Zhao J, Hu Y et al (2020) Clinical features of patients infected with 2019 novel coronavirus in Wuhan China. Lancet 395(10223):497-506

5. Qiu H, Wu J, Hong L, Luo Y, Song Q, Chen D (2020) Clinical and epidemiological features of 36 children with coronavirus disease 2019 (COVID-19) in Zhejiang China: an observational cohort study. Lancet Infect Dis 20(6):689-696

6. Parri N, Lenge M, Buonsenso D (2020) Children with Covid19 in Pediatric Emergency Departments in Italy. N Engl J Med 383(2): 187-190

7. Ludvigsson JF (2020) Children are unlikely to be the main drivers of the COVID-19 pandemic - a systematic review. Acta Paediatr 109(8):1525-1530. https://doi.org/10.1111/apa.15371

8. ONS UK Data (2020) Coronavirus (COVID-19) Infection survey UK: November 6 2020. https://www.ons.gov.uk/ peoplepopulationandcommunity/healthandsocialcare/ conditionsanddiseases/bulletins/coronaviruscovid19infection surveypilot/6november2020. Accessed 15 May 2021

9. Liguoro I, Pilotto C, Bonanni M, Ferrari ME, Pusiol A, Nocerino A, Vidal E, Cogo P. SARS-COV-2 infection in children and newborns: 
a systematic review. Eur J Pediatr 179(7):1029-1046. doi:https:// doi.org/10.1007/s00431-020-03684-7

10. Chen H, Guo J, Wang C, Luo F, Yu X, Zhang W et al (2020) Clinical characteristics and intrauterine vertical transmission potential of COVID-19 infection in nine pregnant women: a retrospective review of medical records. Lancet 395(10226):809-815

11. Vivanti AJ, Vauloup-Fellous C, Prevot S et al (2020) Transplacental transmission of SARS-CoV-2 infection. Nat Commun 11:3572. https://doi.org/10.1038/s41467-020-17436-6

12. Riphagen S, Gomez X, Gonzalez-Martinez C, Wilkinson N, Theocharis P (2020) Hyperinflammatory shock in children during COVID-19 pandemic. Lancet 395(10237):1607-1608. https://doi. org/10.1016/S0140-6736(20)31094-1

13. Toubiana J, Poirault C, Corsia A et al (2020) Kawasaki-like multisystem inflammatory syndrome in children during the covid-19 pandemic in Paris France: prospective observational study. BMJ 369:m2094. https://doi.org/10.1136/bmj.m2094

14. Whittaker E, Bamford A, Kenny J, Kaforou M, Jones CE, Shah P, Ramnarayan P, Fraisse A, Miller O, Davies P, Kucera F, Brierley J, McDougall M, Carter M, Tremoulet A, Shimizu C, Herberg J, Burns JC, Lyall H, Levin M (2020) Clinical characteristics of 58 children with a pediatric inflammatory multisystem syndrome temporally associated with SARS-CoV-2. JAMA 324(3):259-269. https://doi.org/10.1001/jama.2020.10369

15. Brierley J, Playfor S, Ray S (2020) Planning for the next pandemic: a call for new guidance. Lancet Respir Med 8(3):228-229. https://doi.org/10.1016/S2213-2600(19)30357-1

16. ESPNIC (2020) ESPNIC Ethics Section: COVID-19 Pandemic Ethics Statement. https://espnic-online.org/News/Latest-News/ ESPNIC-Ethics-Section-COVID-19-Pandemic-Ethics-Statement. Accessed 15 May 2021

17. DeGrazia D, Beauchamp TL (2010) Philosophy: ethical principles and common morality. In: Sugarman J, Sulmasy D (eds) Methods in Medical Ethics. Georgetown University Press, Washington DC, pp 37-53

18. Sulmasy D, Sugarman J (2010) The many methods of medical ethics (or thirteen ways of looking at a blackbird. In: Sugarman J, Sulmasy D (eds) Methods in Medical Ethics. Georgetown University Press, Washington DC, pp 3-19

19. Bose SK, Dasani S, Roberts SE, Wirtalla C, DeMatteo RP, Doherty GM, Kelz RR (2021) The cost of quarantine: projecting the financial impact of canceled elective surgery on the nation's hospitals. Ann Surg 273(5):844-849

20. Poeran J, Zhong H, Wilson L, Liu J, Memtsoudis SG (2020) Cancellation of elective surgery and intensive care unit capacity in New York State: a retrospective cohort analysis. Anesth Analg 131(5):1337-1341

21. Alsaied T, Aboulhosn JA, Cotts TB, Daniels CJ, Etheridge SP, Feltes TF, Gurvitz MZ, Lewin MB, Oster ME, Saidi A (2020) Coronavirus Disease 2019 (COVID-19) pandemic implications in pediatric and adult congenital heart disease. J Am Heart Assoc 9(12):e017224. https://doi.org/10.1161/JAHA.120.017224

22. Kaur P, Attard TM, Fishman DS, Zapata F, Ditsch D, Thomson M, Schurman JV (2020) A conceptual framework for rescheduling elective pediatric gastroenterology procedures following COVID19 pandemic lockdown. Gastroenterol Nurs 43(5):375-381

23. Peiro-Garcia A, Corominas L, Coelho A, DeSena-DeCabo L, Torner-Rubies F, Fontecha CG (2020) How the COVID-19 pandemic is affecting paediatric orthopaedics practice: a preliminary report. J Child Orthop 14(3):154-160. https://doi.org/10.1302/ 1863-2548.14.200099

24. Regelmann MO, Conroy R, Gourgari E, Gupta A, Guttmann-Bauman I, Heksch R, Kamboj MK, Krishnan S, Lahoti A, Matlock K (2020) Pediatric endocrinology in the time of COVID-19: considerations for the rapid implementation of telemedicine and management of pediatric endocrine conditions. Horm Res Paediatr 93(6):343-350. https://doi.org/10.1159/000513060

25. Chen Y, Kathirithamby DR, Li J, Candelario-Velazquez C, Bloomfield A, Ambrose AF (2021) Telemedicine in the Coronavirus Disease 2019 (COVID-19) pandemic: a pediatric rehabilitation perspective. Am J Phys Med Rehabil 100(4):321-326. https:// doi.org/10.1097/PHM.0000000000001698

26. Kim JW, Lame M, Szalay L, Lefchak B, Johnsson B, Gogia K, Clark S, Kessler D, Leyden D, Sharma R, Platt S (2021) Telemedicine surge for pediatric patients in response to the COVID19 pandemic in New York City. Telemed J E Health. https://doi. org/10.1089/tmj.2020.0413

27. Rosenbaum PL, Silva M, Camden C (2020) Let's notgo back to normal lessons from COVID-19 for professionals working in childhooddisability. Disabil Rehabil 1-7. https://doi.org/10.1080/ 09638288.2020.1862925

28. World Health Organization (2020) Community-based health care, including outreach and campaigns in the context of the COVID-19 pandemic. https://www.who.int/publications-detail/community-basedhealth-care-including-outreach-and-campaigns-in-the-context-of-thecovid-19-pandemic

29. Lin J, Duan J, Tan T, Fu Z, Dai J (2020) The isolation period should be longer: lesson from a child infected with SARS-CoV-2 in Chongqing China. Pediatric Pulmonol 55:6-9

30. Sserwanja Q, Kawuki J, Kim JH (2020) Increased child abuse in Uganda amidst COVID-19 pandemic. J Paediatr Child Health

31. Lazzerini M, Barbi E, Apicella A, Marchetti F, Cardinale F, Trobia G (2020) Delayed access or provision of care in Italy resulting from fear of COVID-19. Lancet Child Adolesc Health 4(5):10-11

32. Snapiri $\mathrm{O}$ et al (2020) Delayed diagnosis of paediatric appendicitis during the COVID-19 pandemic. Acta Paediatr 109(8):16721676. https://doi.org/10.1111/apa.15376

33. Fernandes ND, Cummings BM, Naber CE, Salt MD, Lok J, Yager $\mathrm{PH}$, Carroll RW (2020) Adult COVID-19 Patients cared for in a pediatric ICU embedded in a regional biothreat center: disease severity and outcomes. Health Secur. https://doi.org/10.1089/hs.2020.0225

34. Wasserman E, Toal M, Nellis ME, Traube C, Joyce C, Finkelstein R, Killinger JS, Joashi U, Harrington JS, Torres LK, Greenwald BM, Howell J (2021) Rapid transition of a PICU space and staff to adult coronavirus disease 2019 ICU care. Pediatr Crit Care Med 22(1):50-55. https://doi.org/10.1097/PCC.0000000000002597

35. Deep A, Knight P, Kernie SG, D'Silva P, Sobin B, Best T, Zorrilla M, Carson L, Zoica B, Ahn D (2020) A hybrid model of pediatric and adult critical care during the coronavirus disease 2019 surge: the experience of two tertiary hospitals in London and New York. Pediatr Crit Care Med 22(2):125-134. https://doi.org/10.1097/ PCC.0000000000002584

36. Terheggen U, Heiring C, Kjellberg M, Hegardt F, Kneyber M, Gente M, Roehr CC, Jourdain G, Tissieres P, Ramnarayan P, Breindahl M, van den Berg J (2020) European consensus recommendations for neonatal and paediatric retrievals of positive or suspected COVID-19 patients. Pediatr Res 89:1094-1100. https://doi.org/10.1038/s41390-020-1050-Z

37. Sperotto F, Wolfler A, Biban P, Montagnini L, Ocagli H, Comoretto R, Gregori D, Amigoni A, Italian Network of Pediatric Intensive Care Unit Research Group (TIPNet) (2021) Unplanned and medical admissions to pediatric intensive care units significantly decreased during COVID-19 outbreak in Northern Italy. Eur J Pediatr 180(2):643-648. https://doi.org/ 10.1007/s00431-020-03832-z

38. Jackson C, Mangtani P, Hawker J, Olowokure B, Vynnycky E (2014) The effects of school closures on influenza outbreaks and pandemics: systematic review of simulation studies. PLoS One 9(5):e97297

39. Bin Nafisah S, Alamery AH, Al Nafesa A, Aleid B, Brazanji NA (2018) School closure during novel influenza: a systematic review. J Infect Public Health 11:657-661 
40. Amnesty International (2020) Exposed silenced attacked: failures to protect health and essential workers during the Covid19 pandemic. https://www.amnesty.org/download/Documents/ POL4025722020ENGLISH.PDF. Accessed 15 May 2021

41. Hughes MM, Groenewold MR, Lessem SE et al (2020) Update: characteristics of health care personnel with COVID-19-United States February 12-July 16 2020. Morb Mortal Wkly Rep 69:1364-1368

42. Lai J, Ma S, Wang Y, Cai Z, Hu J, Wei N, Wu J, Du H, Chen T, Li R, Tan H, Kang L, Yao L, Huang M, Wang H, Wang G, Liu Z, Hu S (2020) Factors associated with mental health outcomes among health care workers exposed to coronavirus disease 2019. JAMA Netw Open 3(3):e203976

43. Cacchione PZ (2020) Moral distress in the midst of the COVID19 pandemic. Clin Nurs Res 29(4):215-216

44. Rabbone I, Schiaffini R, Cherubini V, Maffeis C, Scaramuzza A, Diabetes Study Group of the Italian Society for Pediatric Endocrinology and Diabetes (2020) Has COVID-19 Delayed the Diagnosis and Worsened the Presentation of Type 1 Diabetes in Children? Diabetes Care 43(11):2870-2872. https://doi.org/10. 2337/dc20-1321

45. Ding YY, Ramakrishna S, Long AH, Phillips CA, Montiel-Esparza R, Diorio CJ, Bailey LC, Maude SL, Aplenc R, Batra V, Reilly AF, Rheingold SR, Lacayo NJ, Sakamoto KM, Hunger SP (2020) Delayed cancer diagnoses and high mortality in children during the COVID-19 pandemic. Pediatr Blood Cancer 67(9):e28427. https:// doi.org/10.1002/pbc. 28427

46. Vergano $\mathrm{M}$ et al (2020) SIAARTI Clinical ethics recommendations for the allocation of intensive care treatments in exceptional resource-limited circumstances. Minerva Anestesiol 86(5):469-472

47. Truog RD, Mitchell C, Daley GQ (2020) The toughest triageallocating ventilators in a pandemic. N Engl J Med 382(21):1973-1975

48. Blake H, Yildirim M, Wood B, Knowles S, Mancini H, Coyne E, Cooper J (2020) COVID-Well: Evaluation of the implementation of supported wellbeing centres for hospital employees during the COVID-19 pandemic. Int J Environ Res Public Health 17(24):9401

49. Fancourt D, Bu F, Van Mak H et al (2020) Covid 19 social study Results Release 1. University College, London. https:// 746a1e8d-7231-4b96-9bc2-88b2eb5c4964.filesusr.com/ugd/ 3d9db5_a82c3a15441f4687a0114efc78307e80.pdf. Accessed 15 May 2021

50. Rubin GJ, Wessely S (2020) Coronavirus: the psychological effects of quarantining a city. https://blogs.bmj.com/bmj/2020/ 01/24/coronavirus-the-psychological-effects-of-quarantining-acity/. Accessed 15 May 2021

51. Donnelly PD, Davidson M, Dunlop N et al (2020) Well-being during coronavirus disease 2019: a PICU practical perspective Pediatr Crit Care Med 21(8):584

52. Tedesco B, Borgese G, Cracco U, Casarotto P, Zanin A (2020) Challenges to delivering family-centred care during the Coronavirus pandemic: voices of Italian paediatric intensive care unit nurses. Nurs Crit Care. https://doi.org/10.1111/nicc.12578

53. Fegert JM, Vitiello B, Plener PL, Clemens V (2020) Challenges and burden of the Coronavirus 2019 (COVID-19) pandemic for child and adolescent mental health: a narrative review to highlight clinical and research needs in the acute phase and the long return to normality. Child Adolesc Psychiatry Ment Health 14:20. https:// doi.org/10.1186/s13034-020-00329-3

54. UNESCO (2021) Education: From disruption to recovery. https:// en.unesco.org/covid19/educationresponse. Accessed 15 May 2021

55. Viner RM, Russell SJ, Croker H et al (2020) School closure and management practices during coronavirus outbreaks including COVID-19: a rapid systematic review. Lancet Child Adolesc Health 4(5):397-404
56. Golberstein E, Wen H, Miller BF (2020) Coronavirus Disease 2019 (COVID-19) and mental health for children and adolescents. JAMA Pediatr 174(9):819-820. https://doi.org/10.1001/ jamapediatrics.2020.1456

57. Silliman Cohen RI, Bosk EA (2020) Vulnerable youth and the COVID-19 pandemic. Pediatrics 146(1):e20201306. https://doi. org/10.1542/peds.2020-1306

58. UNICEF (2020) Migrant and displaced children in the age of COVID19: How the pandemic is impacting them and what can we do to help. https://www.unicef.org/media/68761/file. Accessed 15 May 2021

59. UNICEF (2020) Technical Note: Protection of children during the coronavirus pandemic. https://www.unicef.org/media/65991/file/ Technical $\% 20$ note: $\% 20$ Protection $\% 20$ of $\% 20$ children $\% 20$ during $\%$ 20the \% 20coronavirus\%20disease $\% 202019 \% 20$ (COVID-19)\% 20pandemic.pdf. Accessed 15 May 2021

60. Ballinger L, Fyfe W (2020) Coronavirus: child vaccine warning over other deadly diseases. https://www.bbc.com/news/uk-wales52457775. Accessed 15 May 2021

61. Hadjipanayis A, Dornbusch HJ, Grossman Z, Theophilou L, Brierley J (2020) Mandatory vaccination: a joint statement of the Ethics and Vaccination working groups of the European Academy of Paediatrics. Eur J Pediatr 179(4):683-687. https:// doi.org/10.1007/s00431-019-03523-4

62. Dror AA, Eisenbach N, Taiber S, Morozov NG, Mizrachi M, Zigron A, Srouji S, Sela E (2020) Vaccine hesitancy: the next challenge in the fight against COVID-19. Eur J Epidemiol 35(8):775-779. https://doi.org/10.1007/s10654-020-00671-y

63. COCONEL Group (2020) A future vaccination campaign against COVID-19 at risk of vaccine hesitancy and politicisation. Lancet Infect Dis 20(7):769-770. https://doi.org/10.1016/S14733099(20)30426-6

64. Oviedo Convention (1997) Convention for the protection of Human Rights and Dignity of the Human Being with regard to the Application of Biology and Medicine: Convent Human Rights Biomed. https://www. coe.int/en/web/conventions/full-list//conventions/treaty/164module= treaty-detailtreatynum $=164$. Accessed on the 15 of May 2021

65. Beauchamp TL, Childress JF (2019) Principles of biomedical ethics, 8th edn. Oxford University Press, New York

66. Thompson A (2006) Stand on Guard for Thee: Ethical Considerations in Preparedness Planning for Pandemic Influenza. University of Toronto Joint Centre for Bioethics Pandemic Influenza Working Group. https://www.calhospitalprepare.org/sites/main/files/fileattachments/5-03-06_stand_on_guard_for_thee_sars_thomopson. pdf. Accessed on the 15 of May 2021

67. Emanuel EJ, Persad G, Upshur R, Thome B, Parker M, Glickman A et al (2020) Fair allocation of scarce medical resources in the time of Covid-19. N Engl J Med 382(21):2049-2055

68. Bressan S, Buonsenso D, Farrugia R, Parri N, Oostenbrink R, Titomanlio L et al (2020) Preparedness and response to Pediatric CoVID-19 in European Emergency Departments: a survey of the REPEM and PERUKI networks. Ann Emerg Med 76(6):788-800

69. Sainati L, Biffi A (2020) How we deal with the COVID-19 epidemic in an Italian paediatric onco-haematology clinic located in a region with a high density of cases. Br J Haematol 189(4):640-642

70. Thomas JP, Srinivasan A, Wickramarachchi CS, Dhesi PK, Hung YM, Kamath AV (2020) Evaluating the national PPE guidance for NHS healthcare workers during the COVID-19 pandemic. Clin Med 20(3):242

71. Brierley J, Larcher V (2021) The Birkenhead drill suggests women and children first: government and society's reversal of the drill during the COVID-19 pandemic left children last and cannot be allowed to continue. Postgrad Med J 97(1144):119-122. https:// doi.org/10.1136/postgradmedj-2020-137991

Publisher's Note Springer Nature remains neutral with regard to jurisdictional claims in published maps and institutional affiliations. 